\title{
Topics of interest to the MSOR community: evidence from the first 20 years of MSOR Connections
}

Peter Rowlett, Department of Engineering and Mathematics, Sheffield Hallam University, Sheffield, UK. Email: p.rowlett@shu.ac.uk ORCID: https://orcid.org/0000-0003-1917-7458

Alexander S. Corner, Department of Engineering and Mathematics, Sheffield Hallam University, Sheffield, UK. Email: alex.corner@shu.ac.uk ORCID: https://orcid.org/0000-0001-6222-3443

\begin{abstract}
Topic modelling, an automated literature review technique, is used to generate a list of topics from the text of all articles published in previous issues of MSOR Connections. There are many topics of consistent popularity, including assessment, employability, school-university transition and the teaching of specific subjects and skills with the mathematics, statistics and operational research disciplines. We identify some topics that have waned in popularity, especially following the demise of the MSOR Network, including organised book and software reviews, conference and workshop announcements and reports, and articles focused on staff development. In its present form as a fully peer-reviewed practitioner journal, there appears to be a shift in focus from personal reflection to evidence-based research. There is a high focus on innovative practice using technology in the publication, though with less focus on specific software over time. Similarly, more nuance appears to be entering the discourse over maths support and e-assessment as these topics mature. We note a rise over time in student-centred approaches and a sudden rise in the previous issue of digital and remote learning due to the COVID-19 pandemic. We speculate about future trends that may emerge, including an increased focus on digital and remote learning and an increase in content on equity, equality, diversity and inclusion.
\end{abstract}

Keywords: Topic modelling, review, history of mathematics education.

\section{Introduction}

The first issue of MSOR Connections was published in February 2001, and the most recent issue was published in January 2021. This means the 62 issues published prior to the current one span a 20 year period. Recently, we have been impressed by insights into mathematics education research papers using a method called topic modelling (Inglis and Foster, 2018; Marks et al., 2021), which attempts to determine key topics from a large corpus of documents. This 20th anniversary of MSOR Connections seems an ideal time to apply this method to the archive of articles published in this journal, in hopes of identifying for the benefit of the community the topics which are discussed in MSOR Connections and changes over time in their popularity. By highlighting what we as a community have been talking about, we hope we might provide a prompt for reflection by future authors in the journal about topics either commonly studied or under-studied.

\section{Background}

In 2000, the Learning and Teaching Support Network (LTSN) established a series of 24 subject centres aiming to collect and share "good practice, experience and innovation in a coherent and accessible form" (Allan, 2000). One of these centres was the Maths, Stats and OR (MSOR) Network, comprising elements of the previous Computers in Teaching Initiative centres in mathematics and statistics and linked to the RSS Centre for Statistical Education (Blake, Davies and Bishop, 2000). The new subject centre established a newsletter called Maths, Stats \& OR, which published four issues in 2000 before being relaunched as MSOR Connections with volume 1 issue 1 published in 
February 2001 and each volume covering a calendar year thereafter. (Thus the MSOR Network had its Connections, a serviceable pun somewhat lost on new readers nowadays!) Volumes 1-9 contained four issues, volumes 10-11 contained three issues and volume 12 contained two issues. MSOR Connections served as the newsletter of the MSOR Network and also as a practitioner journal for the community it served. The MSOR Network and MSOR Connections survived the incorporation of LTSN into the new Higher Education Academy (HEA) in 2004 (Blake, 2004), and continued until the HEA closed the subject centres in 2012 (Waller, 2012).

The HEA relaunched MSOR Connections in 2013 as a peer-reviewed journal aiming to "promote, encourage, enhance and disseminate research, good practice and innovation in all aspects of the student learning experience within Mathematics, Statistics and Operational Research wherever these may be taught in Higher Education" (Kyle, 2013a). This iteration of MSOR Connections published just two issues in 2013.

In 2015, the journal was relaunched as a community initiative supported by the sigma Network and the University of Greenwich, which remains its current form. In a change to previous practice, a volume now covers an academic year. This iteration maintained MSOR Connections as a peerreviewed, online-only, practitioner journal focused on "research articles, case studies and opinion pieces relating to innovative learning, teaching, assessment and support in Mathematics, Statistics and Operational Research from across HE" (Wilson, 2015). Volumes 14-18 contained three issues, with one issue of volume 19 published to date.

\section{Method}

\subsection{Topic modelling}

Topic modelling is explained in more detail elsewhere (e.g. Griffiths and Steyvers, 2004); here we give a flavour. Assume that a corpus of text documents are formed by selecting words from a number of topics, where each document has a set distribution of these words. So document 1 might select $50 \%$ of words from topic 1, 30\% from topic 2 and $20 \%$ from topic 3, while document 2 might select $25 \%$ of words from each of topics 1 and 2 and $50 \%$ from topic 3, etc. Topic modelling takes an existing set of documents and attempts to generate the topics from which these might have been formed by assigning words from the articles into groupings. An advantage of this method is that there is no presumption about the topics that will emerge, so what results is theoretically an unbiased representation of the documents under study. As well as grouping words into topics, the method also assigns to each document the proportions of its text that are drawn from each topic, meaning the composition of each document can be studied. Subsequently, it is possible to review each topic and manually assign it a collective name, which aids interpretation.

An attraction of the approach is the efficiency of automation. A manual review of either metadata (titles and abstracts) or whole articles would yield richer data that could provide greater meaning in a qualitative analysis, but a review of nearly a thousand articles in this way would be onerous. Using this approach, we manually reviewed around 5-10 articles in each of our categories, with the rest left to automation.

One issue with topic modelling is that it requires the specification in advance of the number of topics to be generated, and methods for deciding how many topics to model are quite vague. One approach is to run the modelling with different numbers of topics and calculate the resultant perplexity. This measure "indicates the uncertainty in predicting a single word; lower values are better, and chance performance results in a perplexity equal to the size of the vocabulary" (Griffiths and Steyvers, 2004; p. 5230). Inglis and Foster explain "it is always possible to reduce the perplexity of a topic model by increasing the number of topics, but, at some point, the gain in fit will be offset by the increased 
difficulty of interpreting the larger number of topics", stressing that a major criterion for selecting the number is the interpretability of the resulting topics (p. 470).

We used MALLET 2.0.8 (McCallum, 2002), a toolkit for topic modelling, for this analysis.

\subsection{Locating and processing files}

The public location of articles of MSOR Connections is a complicated picture. During its history, it has been published by three bodies: volumes $1-12$ by the University of Birmingham (holder of the MSOR Network contract); volume 13 by the Higher Education Academy; and, since volume 14, by the University of Greenwich on behalf of sigma.

When it was closed in 2012, the MSOR Network's website was archived by the Royal Statistical Society Centre for Statistical Education at the University of Plymouth, which later became the International Centre for Statistical Education and then itself closed in 2016 (International Centre for Statistical Education, 2016). Happily, the website archive is still active at http://icse.xyz/mathstore/ and contains an index of MSOR Connections articles.

Files downloaded from this archive were compared with a complete set of printed issues of MSOR Connections volumes 1-12. Where the number of PDFs differed from the number of articles in an issue, this was investigated. Often this happened because articles were combined in the same PDF file (perhaps because a short article shared a page with another), though there were a small number of cases where the article was simply missing from the MSOR Network website. Most of these missing articles were sourced instead from the Advance HE Knowledge Hub https://www.advancehe.ac.uk/knowledge-hub, an archive of HEA subject centre content (though note there are articles missing from the Knowledge Hub that do appear on the MSOR Network website, so neither offers a subset of the other). Five articles were not available in either location online, three of which have been obtained from personal contacts. This leaves two articles (Tyrrell, 2009; Hakim, 2010) that appear in the printed publications but are not available digitally, so were not included in the corpus analysed for this project.

When the Higher Education Academy relaunched MSOR Connections and other subject centre publications, it made a new website at http://journals.heacademy.ac.uk/ to host articles (Kyle, 2013b), assigning these articles DOI numbers (Kyle, 2013a). Unfortunately, this website was subsequently taken offline and the DOI references were not updated to new file locations, though all articles from a printed copy of volume 13 were found via searches on the Advance HE Knowledge Hub. Each article is in a separate PDF file.

All articles from 14(1) to 19(1) were sourced from the current journal website https://journals.gre.ac.uk/index.php/msor/. Each article is in a separate PDF file.

It is worth noting that the frequency of articles published has not remained constant over time, with more articles published in earlier volumes, but also that articles have tended to get longer on average over time, as shown in table 1. The fact that earlier volumes contained more, shorter articles than later ones might mean that they naturally exhibit greater diversity of topics.

From each article in volumes 1-12, the 'welcome' and 'diary' pages were removed and for volumes 13-19 the editorial and contents pages were removed. This is because these files contained only non-article content or content derivative of what is in the articles themselves (table of contents, editorial message and information about the MSOR Network). Advertisements for conferences, workshops and mathematical software were left in the corpus. These were much harder to identify, 
with small advertisements often included in article PDFs, and we feel are sufficiently relevant to the interests of the community at their time and small enough to not bias the findings here.

Table 1. Information on documents in the corpus from each volume.

\begin{tabular}{|c|c|c|c|c|}
\hline Volume & $\begin{array}{c}\text { Years } \\
\text { published }\end{array}$ & $\begin{array}{c}\text { Number of } \\
\text { documents* }\end{array}$ & $\begin{array}{l}\text { Total words }{ }^{* *} \text { in } \\
\text { documents }\end{array}$ & $\begin{array}{l}\text { Average words }{ }^{\star *} \\
\text { per document }\end{array}$ \\
\hline 1 & 2001 & 72 & 133592 & 1855 \\
\hline 2 & 2002 & 77 & 137409 & 1785 \\
\hline 3 & 2003 & 91 & 143950 & 1582 \\
\hline 4 & 2004 & 83 & 123776 & 1491 \\
\hline 5 & 2005 & 72 & 104273 & 1448 \\
\hline 6 & 2006 & 70 & 112119 & 1602 \\
\hline 7 & 2007 & 58 & 95717 & 1650 \\
\hline 8 & 2008 & 55 & 100147 & 1821 \\
\hline 9 & 2009 & 56 & 123559 & 2206 \\
\hline 10 & 2010 & 50 & 94604 & 1892 \\
\hline 11 & 2011 & 59 & 83964 & 1423 \\
\hline 12 & 2012 & 33 & 63090 & 1912 \\
\hline 13 & 2013 & 16 & 44370 & 2773 \\
\hline 14 & $2015 / 16$ & 22 & 59728 & 2715 \\
\hline 15 & $2016 / 17$ & 28 & 88186 & 3150 \\
\hline 16 & $2017 / 18$ & 22 & 79058 & 3594 \\
\hline 17 & $2018 / 19$ & 25 & 83171 & 3327 \\
\hline 18 & $2019 / 20$ & 21 & 80434 & 3830 \\
\hline 19 (issue 1 only) & $2020 / 21$ & 8 & 26350 & 3294 \\
\hline
\end{tabular}

* the number of documents does not precisely match the number of articles due to a small number of occasions where multiple articles are presented in the same PDF file in volumes 1-12. ** rough word count: this is the word count of all content in the PDF file after it was converted to plain text and should be considered approximate.

Over all issues, 918 PDFs were obtained. (Note that, for reasons discussed above, this does not map neatly onto the number of articles published, though it is close.) These include articles sharing practice and also conference and workshop reports, book and software reviews, and updates on activities of the MSOR Network and projects from members of the community. As such, the results of this study should be seen to reflect the interests of this community, not just the outputs of a research programme.

The PDF documents were converted to plain text using the Linux utility pdftotext. 
We set MALLET to ignore words on its default English 'stop list', a list of 524 common words which are not likely to be topic-related (for an idea of these, a command to return three random words from this file returned "too", "their" and "unlikely"). We also removed from the documents the following information:

- Information commonly found in footers of articles. These come in different formats during the run of MSOR Connections, for example "MSOR Connections Vol 2 No 2 May 2002", "MSOR Connections Vol 11 No 1 Spring Term 2011", "MSOR Connections, Vol 13, Issue 1 (April 2013)" and "MSOR Connections 16(3) - journals.gre.ac.uk". These words were removed after initial tests found topic matches including words such as "msor", "connections", "vol" and the names of months.

- Author names. Some authors are prolific in the text, particularly MSOR Network staff in volumes 1-12. The index of articles from the MSOR Network website was processed, yielding 553 unique names. From these, surnames were removed from the corpus except where these were short (up to 3 characters) or common words (e.g. "Power", "Ireland" or "Newton"). Again, some trial output had included author names and the aim here was to avoid the method producing a topic that is, for example, 'articles by or citing Chris Sangwin'; we would rather focus the model on the article content.

Viewing the perplexity for up to 50 topics (see figure 1), we identified a drop around 30 topics and so one of us (PR) completed an initial assessment of the topic keywords for 30 topics, finding that there were some that appeared indistinct, for example there appeared to be two topics relating to workshops and conferences and three relating to running a maths support centre, as well as two or three topics that seemed a little generic. For this reason, 25 topics was felt to be adequate. The reduction in perplexity for adding many more topics is not large, and the 25 topics seemed sensible to interpret.

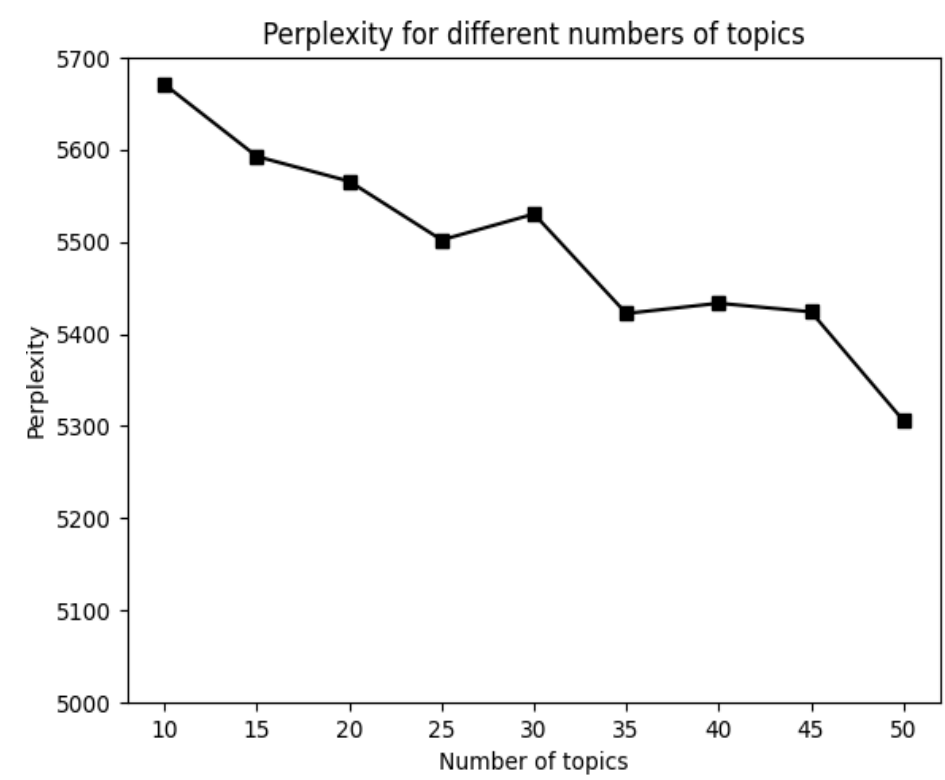

Figure 1. Perplexity of topic models for different numbers of topics.

The five articles with the highest proportion of words from each of the 25 topics were identified and stored along with the most common keywords associated with each topic. Both authors independently reviewed these and assigned names to each topic, then we discussed our lists. Nine topics were assigned with immediate agreement and a further fourteen with minor tweaks to 
phrasing; on two topics we differed meaningfully and these were resolved following brief discussion. This was informed by examining the documents with the highest proportion of words matched from this topic, though note that this is a simplistic process with issues. Some words have multiple meanings, some papers happen to contain words that appear relevant to a topic even though the paper overall might be an outlier. Also it may be that some papers have the highest proportion of relevant words, but are not necessarily indicative of the majority of papers matching that topic, which might have the topic as a minority element. For all topics we examined the five papers with the highest proportion of words from that topic; for those where further insight was needed, we looked at more papers as necessary.

\section{Results}

The list of topics with agreed labels is shown in table 2, along with the most common words associated with each topic. For each topic, we plotted the proportion of words in each volume of MSOR Connections that matched this topic and, as a simple indicator of trends, fitted each with a polynomial trend line. Figure 2 contains these plots using the same axis scales for ease of comparison. The period since the MSOR Network closed and MSOR Connections was relaunched as a fully peer-reviewed practitioner journal is shaded. This gives an indication of the popularity of each topic over time, though note that although volumes are a chronological progression, they are not quite linear; dates for each volume are given in table 1. Note that volume 19 has only published one issue of eight articles to date and the topics of these articles can cause sudden dramatic increases or decreases in the trend lines.

Table 2. Agreed list of named topics with the top characteristic words generated by the model.

\begin{tabular}{|c|c|}
\hline Topic name & Top characteristic words \\
\hline Assessment & $\begin{array}{l}\text { assessment project learning students projects good year report work student } \\
\text { writing criteria skills reports practice group final marking outcomes research }\end{array}$ \\
\hline Book and software reviews & $\begin{array}{l}\text { book material chapter matlab examples text exercises chapters student section } \\
\text { page authors computing review introduction web teaching applets pages software }\end{array}$ \\
\hline Computational software & $\begin{array}{l}\text { maple version user software code file package mathematica users web features } \\
\text { fig review files program tools java output windows tool }\end{array}$ \\
\hline Conferences and workshops & $\begin{array}{l}\text { conference mathematics university education research international group umtc } \\
\text { mathematical computer issues teaching papers sessions delegates technology } \\
\text { loughborough event dyscalculia workshop }\end{array}$ \\
\hline Digital and remote learning & $\begin{array}{l}\text { online video students audio digital university learning technology videos virtual } \\
\text { accessed student screencasts screen time tablet media open technologies pdf }\end{array}$ \\
\hline E-assessment question design & $\begin{array}{l}\text { questions test question tests students quiz student diagnostic answer errors } \\
\text { results correct answers exam feedback fig mark score set scores }\end{array}$ \\
\hline $\begin{array}{l}\text { E-assessment systems and } \\
\text { technologies }\end{array}$ & $\begin{array}{l}\text { assessment questions system mathematics question feedback computer } \\
\text { mathematical caa learning input systems numbas e-assessment marking } \\
\text { university answer answers stack implementation }\end{array}$ \\
\hline $\begin{array}{l}\text { Game play, outreach and the } \\
\text { interaction of the two }\end{array}$ & $\begin{array}{l}\text { maths school pupils mathematical university schools games mathematics } \\
\text { activities game space science teachers activity arcade strategy outreach london } \\
\text { project scheme }\end{array}$ \\
\hline $\begin{array}{l}\text { Graduate employability and } \\
\text { skills development }\end{array}$ & $\begin{array}{l}\text { skills mathematical curriculum development project graduate graduates work } \\
\text { study sciences employers employability education degree careers business stem } \\
\text { studies case developing }\end{array}$ \\
\hline
\end{tabular}


Table 2. Agreed list of named topics with the top characteristic words generated by the model.

\begin{tabular}{|c|c|}
\hline Topic name & Top characteristic words \\
\hline $\begin{array}{l}\text { Interactive lecture technology, } \\
\text { including classroom voting } \\
\text { systems }\end{array}$ & $\begin{array}{l}\text { students lecturer questions lectures class system lecture technology learning } \\
\text { teaching response question classroom student feedback interactive answer } \\
\text { answers systems evs }\end{array}$ \\
\hline $\begin{array}{l}\text { Mathematics on the web, } \\
\text { including impact on accessibility }\end{array}$ & $\begin{array}{l}\text { mathml latex text mathematics mathematical braille web content accessibility } \\
\text { software xml notes access format word accessed visual equation read accessible }\end{array}$ \\
\hline $\begin{array}{l}\text { Maths support interventions to } \\
\text { improve confidence and address } \\
\text { anxiety }\end{array}$ & $\begin{array}{l}\text { maths tutors support tutor students msc training sessions mathematics numeracy } \\
\text { anxiety mls workshop workshops ireland postgraduate drop-in nursing university } \\
\text { participants }\end{array}$ \\
\hline Maths support provision & $\begin{array}{l}\text { support mathematics students centre university engineering provision sigma } \\
\text { institutions student mathematical learning staff centres resources maths statistics } \\
\text { service universities provided }\end{array}$ \\
\hline $\begin{array}{l}\text { Modelling, simulation and } \\
\text { industrial problems }\end{array}$ & $\begin{array}{l}\text { engineering quality business engineers modelling design problems world control } \\
\text { industry system project model projects company public team society } \\
\text { management international }\end{array}$ \\
\hline Online resources & $\begin{array}{l}\text { project resources maths website university information web learning resource } \\
\text { materials Itsn page site material stats online issue details contact email }\end{array}$ \\
\hline $\begin{array}{l}\text { Personal reflections of students } \\
\text { and staff }\end{array}$ & $\begin{array}{l}\text { good time teaching make maths work find problems experience years give things } \\
\text { people interesting found university don't notes problem learn }\end{array}$ \\
\hline $\begin{array}{l}\text { Problem-solving and } \\
\text { mathematical approaches }\end{array}$ & $\begin{array}{l}\text { students learning mathematics mathematical education problem research } \\
\text { understanding teaching problems knowledge thinking study teacher concepts } \\
\text { teachers develop solving approach examples }\end{array}$ \\
\hline Proof, skills and understanding & $\begin{array}{l}\text { mathematics mathematical proof theory examples students mathematicians } \\
\text { proofs analysis theorem definitions numbers set language concept topic } \\
\text { understanding history class physical }\end{array}$ \\
\hline School-university transition & $\begin{array}{l}\text { mathematics students level year mathematical schools courses universities } \\
\text { curriculum subject subjects university school higher a-level education study } \\
\text { engineering modules units }\end{array}$ \\
\hline Staff development & $\begin{array}{l}\text { teaching mathematics statistics education learning network university } \\
\text { development staff research msor support higher practice community work } \\
\text { programme centre activities training }\end{array}$ \\
\hline Statistical data analysis & $\begin{array}{l}\text { data statistics statistical analysis probability regression minitab distribution test } \\
\text { methods fig sample results distributions model set introductory hypothesis } \\
\text { teaching random }\end{array}$ \\
\hline Student evaluation data & $\begin{array}{l}\text { survey data table responses study results online questionnaire higher asked } \\
\text { respondents questions response research education question performance } \\
\text { reported analysis found }\end{array}$ \\
\hline $\begin{array}{l}\text { Student-centred approaches, } \\
\text { including group work and peer } \\
\text { support }\end{array}$ & $\begin{array}{l}\text { students student year module group work staff time mathematics feedback } \\
\text { groups engagement modules teaching learning week class study lectures } \\
\text { sessions }\end{array}$ \\
\hline $\begin{array}{l}\text { Teaching specific curriculum } \\
\text { items }\end{array}$ & $\begin{array}{l}\text { students time number university case important general information provide form } \\
\text { problems order part approach student present terms made common process }\end{array}$ \\
\hline $\begin{array}{l}\text { Teaching specific curriculum } \\
\text { items using technology }\end{array}$ & $\begin{array}{l}\text { geogebra function functions programming linear fig calculus solution equations } \\
\text { algebra integration problem equation point numerical differential complex values } \\
\text { points algebraic }\end{array}$ \\
\hline
\end{tabular}




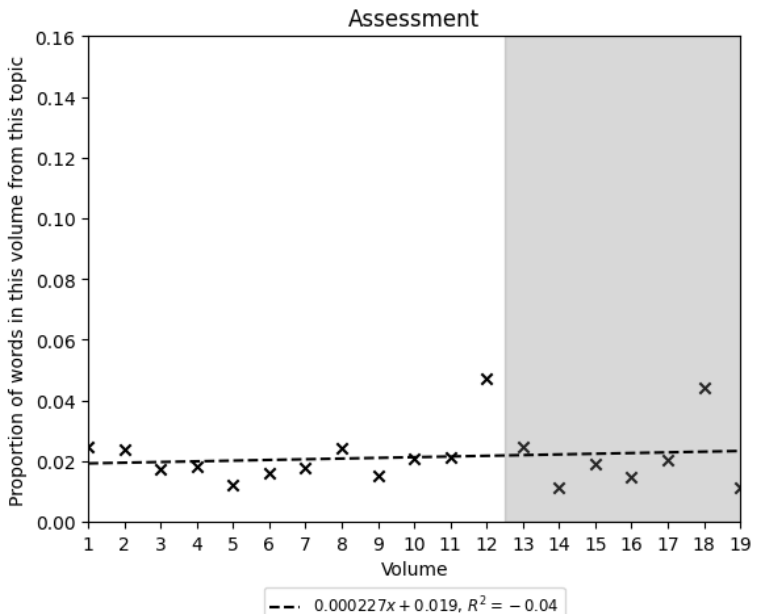

(a)

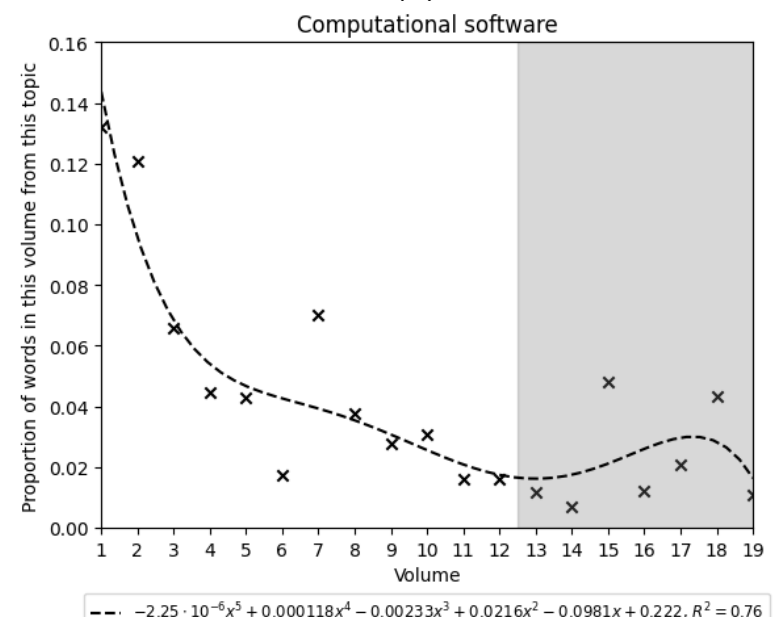

(c)

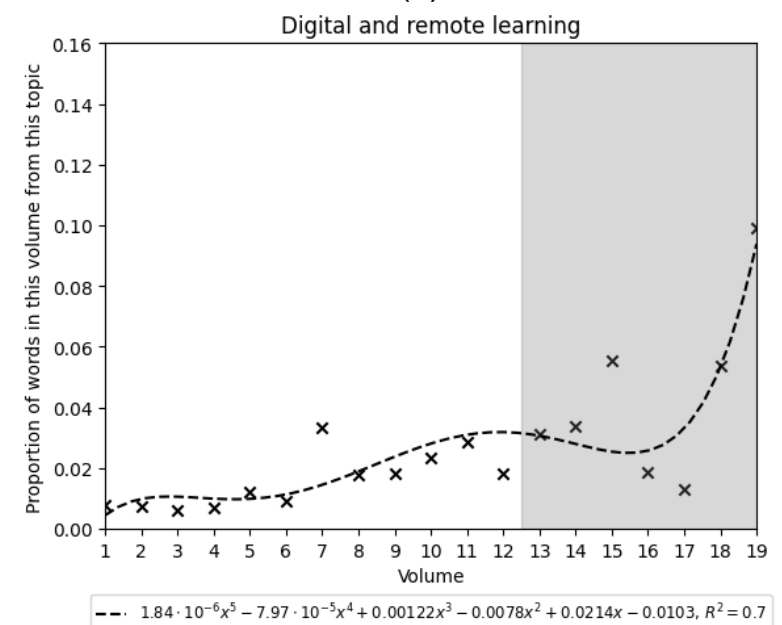

(e)

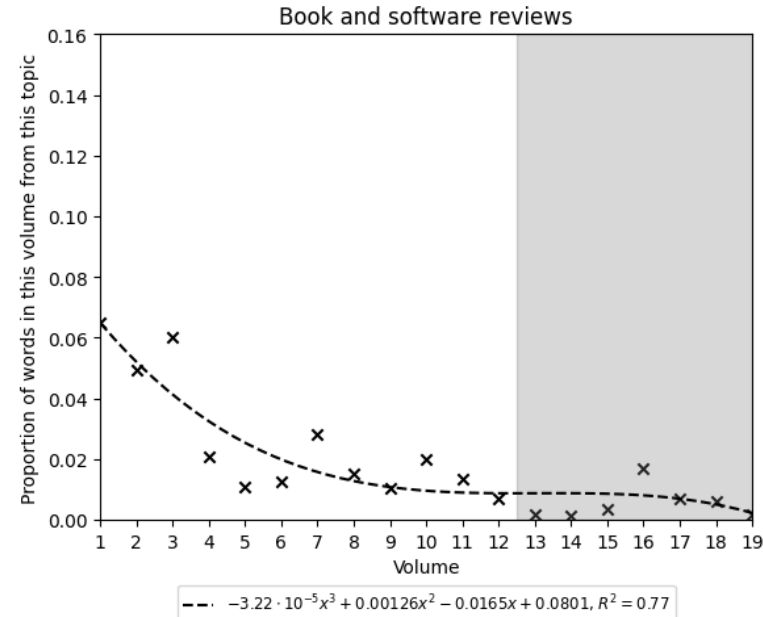

(b)

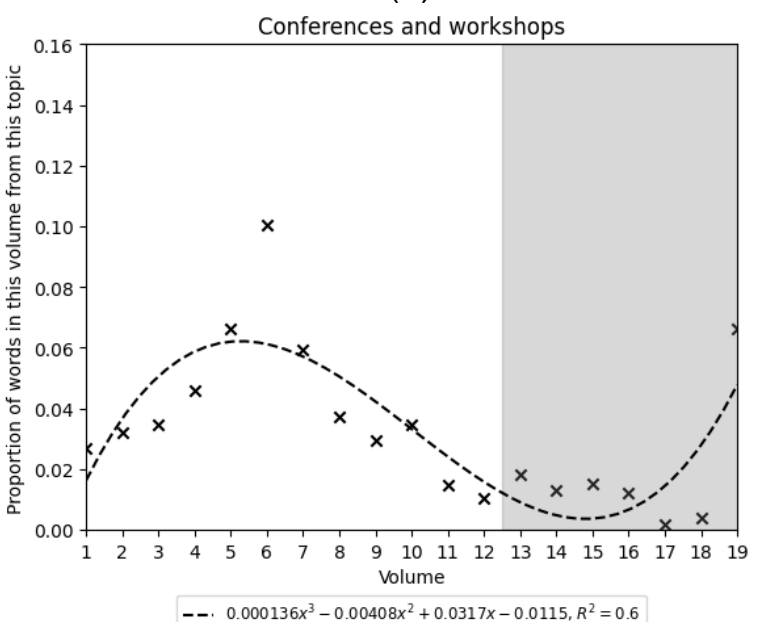

(d)

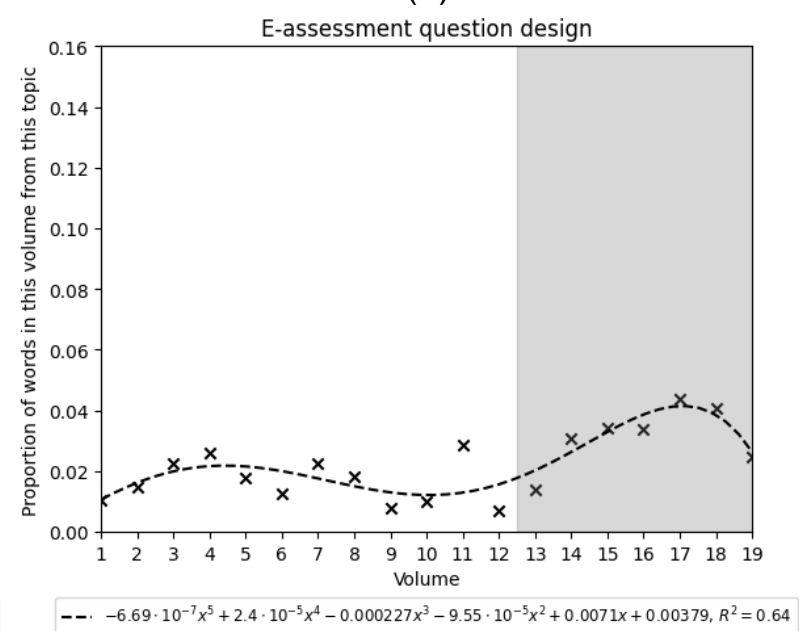

(f)

Figure 2. Proportion of words in each volume that relate to each topic. Trend lines are the polynomials with degree up to 5 that had the best fit (measured by $R^{2}$ ). Shaded region represents the period since the MSOR Network closed and MSOR Connections was relaunched as a fully peer-reviewed practitioner journal. 


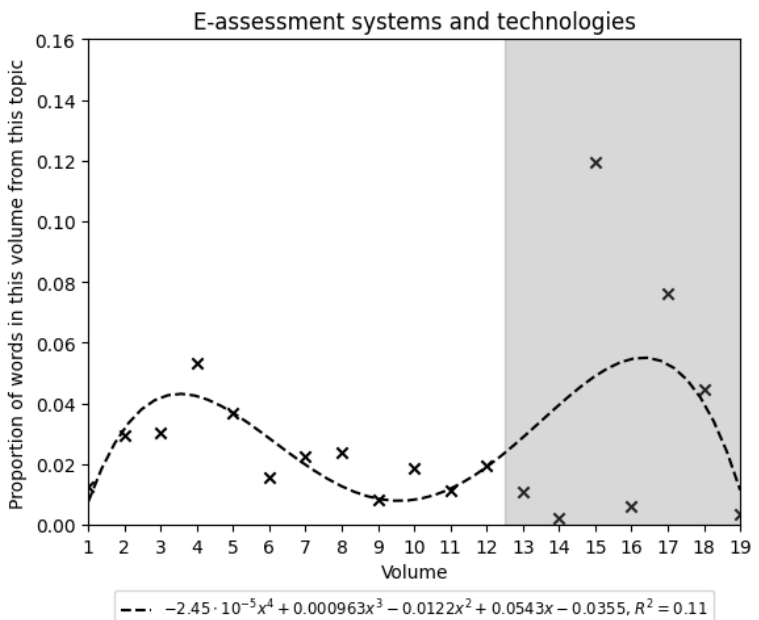

(g)

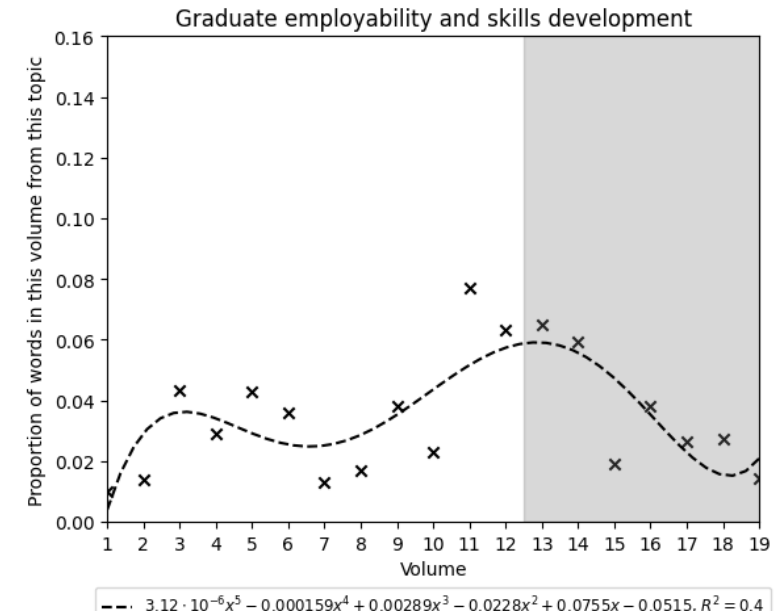

(i)

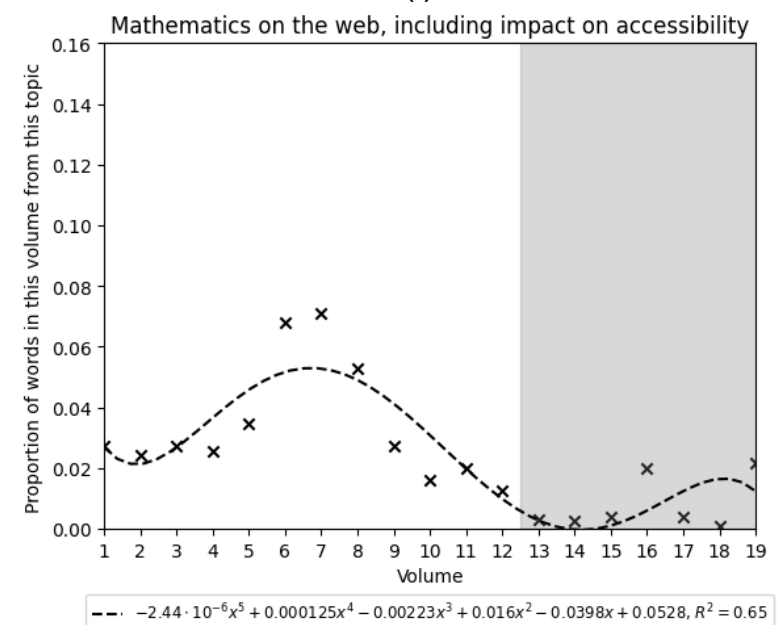

$(\mathrm{k})$

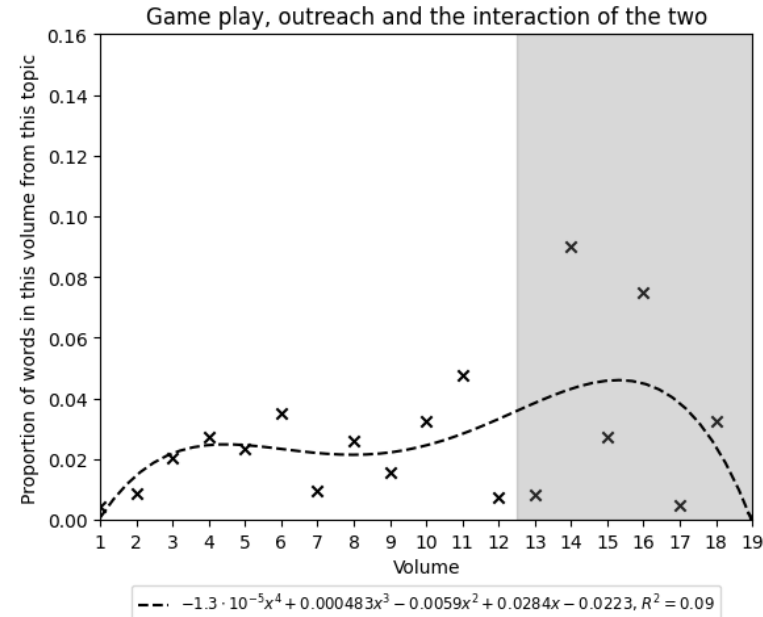

(h)

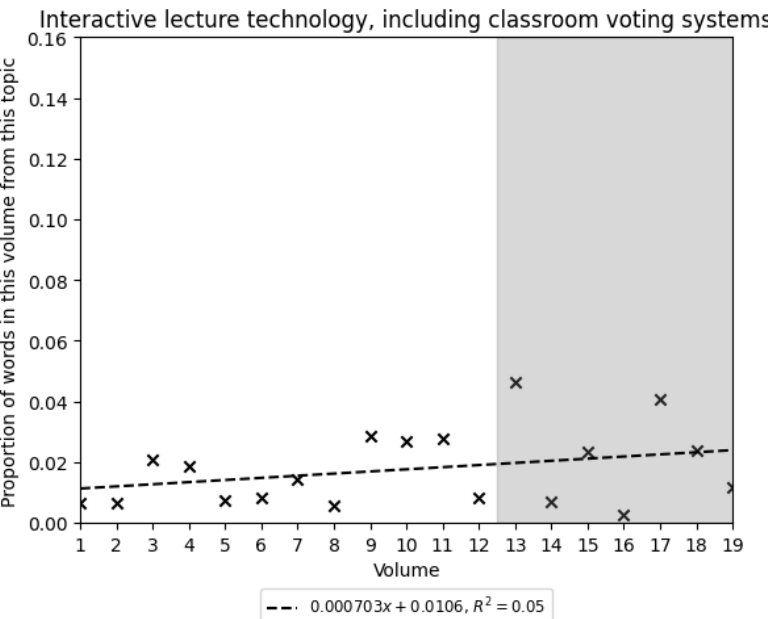

(j)

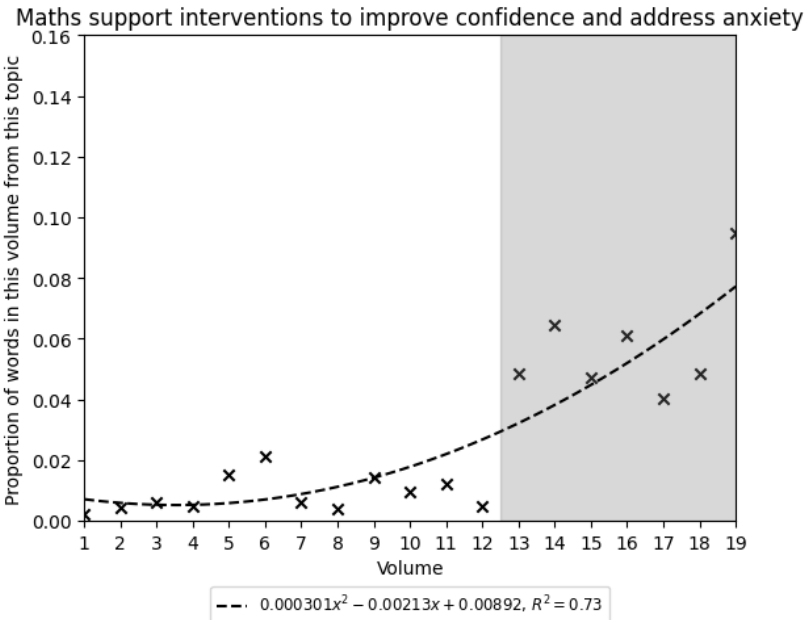

(l)

Figure 2. Proportion of words in each volume that relate to each topic. Trend lines are the polynomials with degree up to 5 that had the best fit (measured by $\mathrm{R}^{2}$ ). Shaded region represents the period since the MSOR Network closed and MSOR Connections was relaunched as a fully peer-reviewed practitioner journal. 


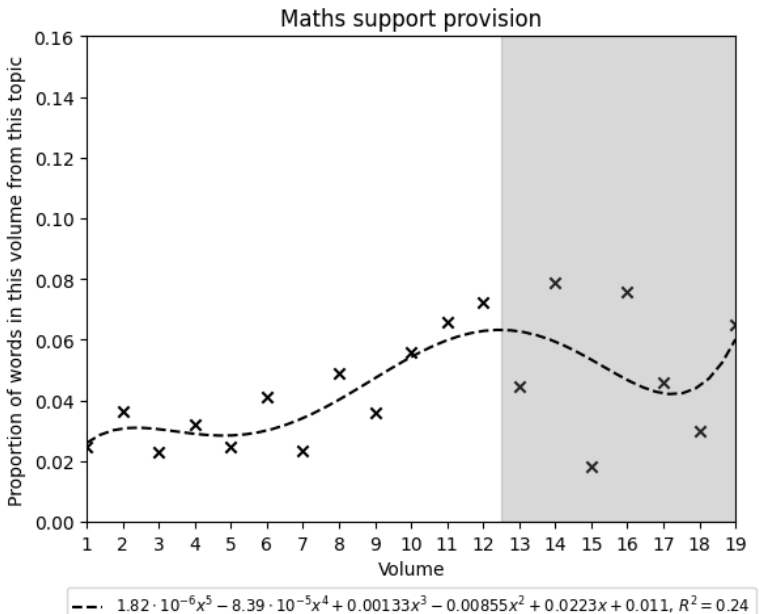

$(\mathrm{m})$

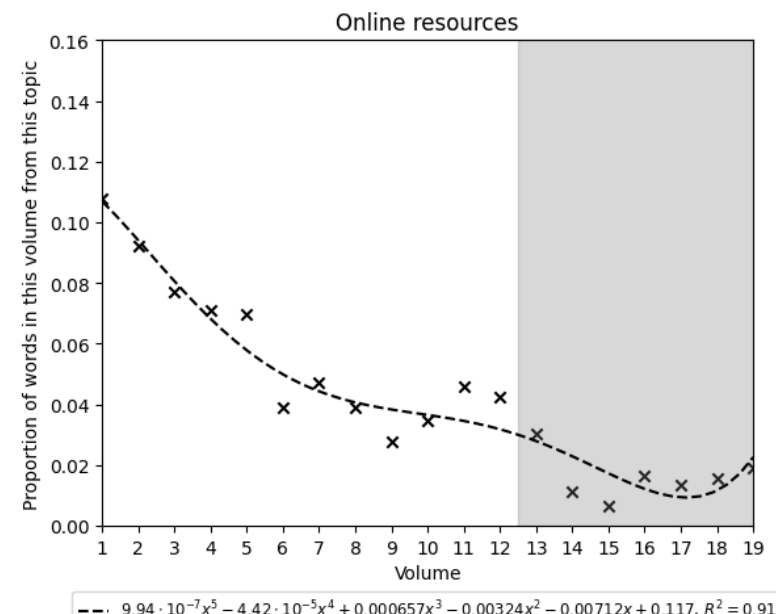

(0)

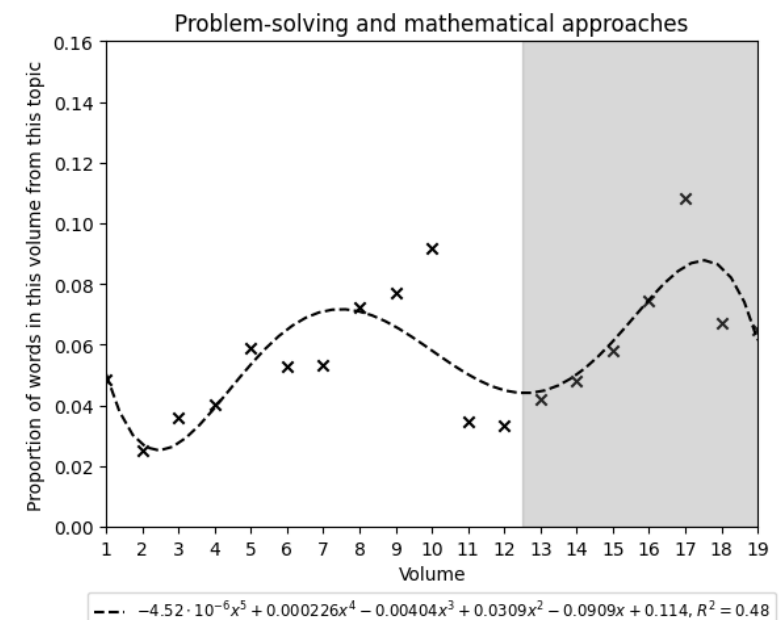

(q)

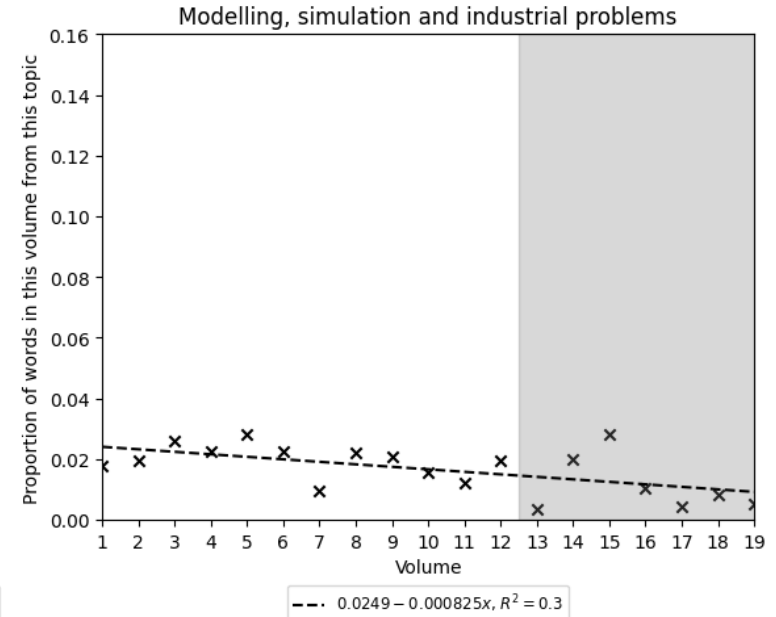

(n)

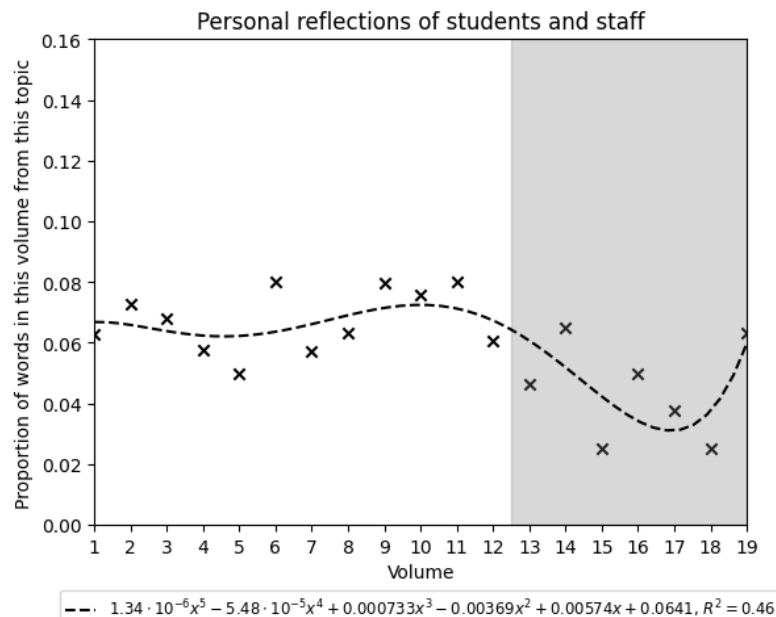

(p)

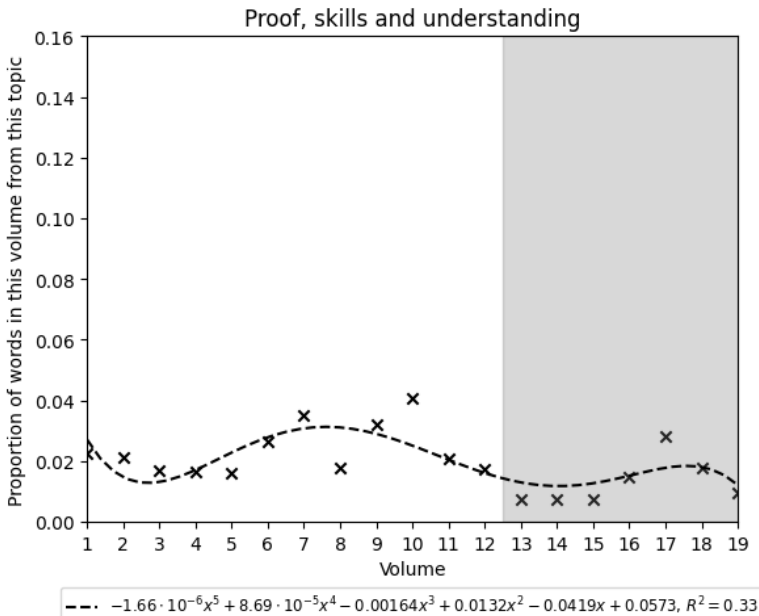

$(r)$

Figure 2. Proportion of words in each volume that relate to each topic. Trend lines are the polynomials with degree up to 5 that had the best fit (measured by $\mathrm{R}^{2}$ ). Shaded region represents the period since the MSOR Network closed and MSOR Connections was relaunched as a fully peer-reviewed practitioner journal. 


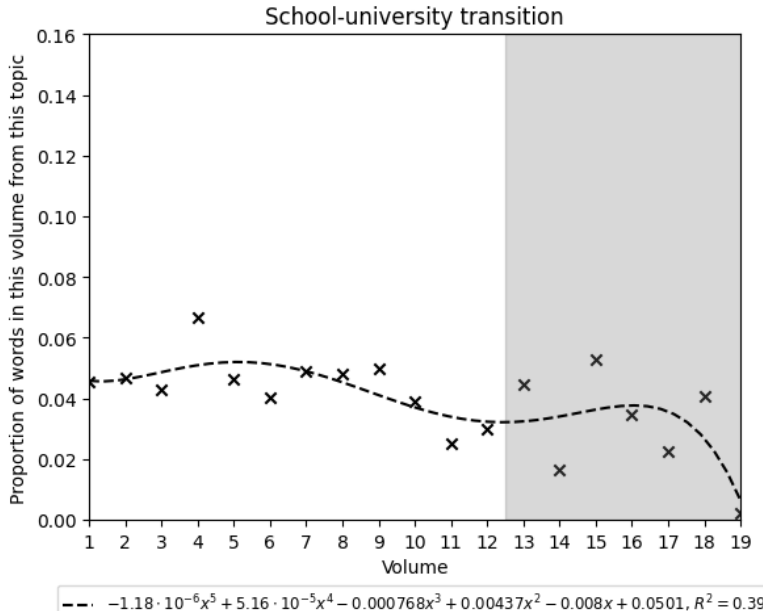

(s)

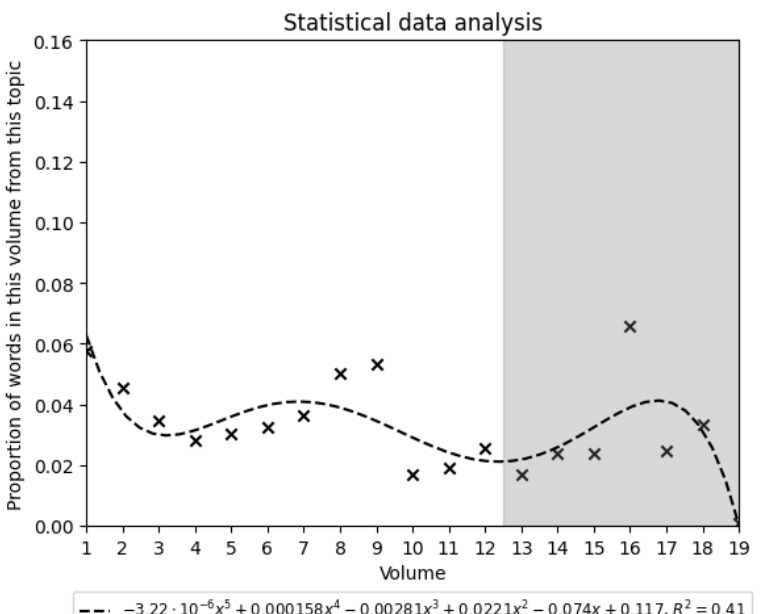

(u)

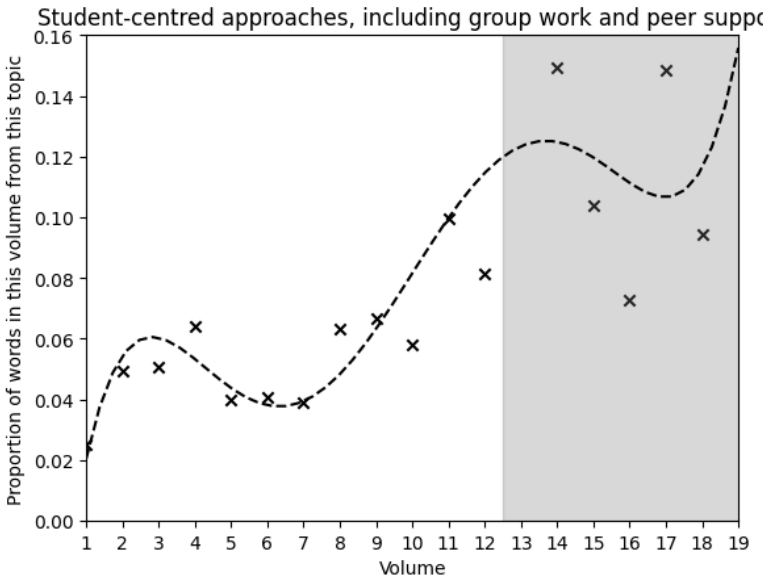

--. $5.54 \cdot 10^{-6} x^{5}-0.000276 x^{4}+0.0049 x^{3}-0.037 x^{2}+0.114 x-0.0616, R^{2}=0.66$

(w)

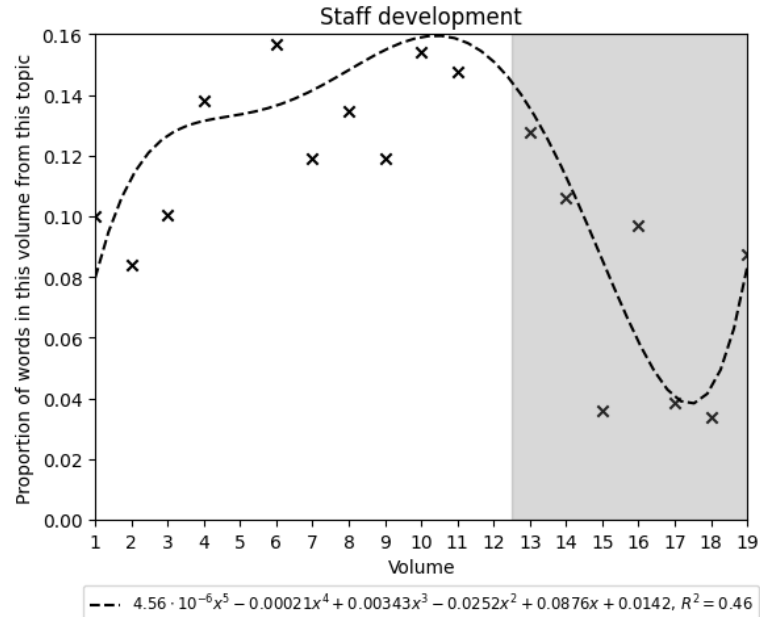

( $\mathrm{t})$

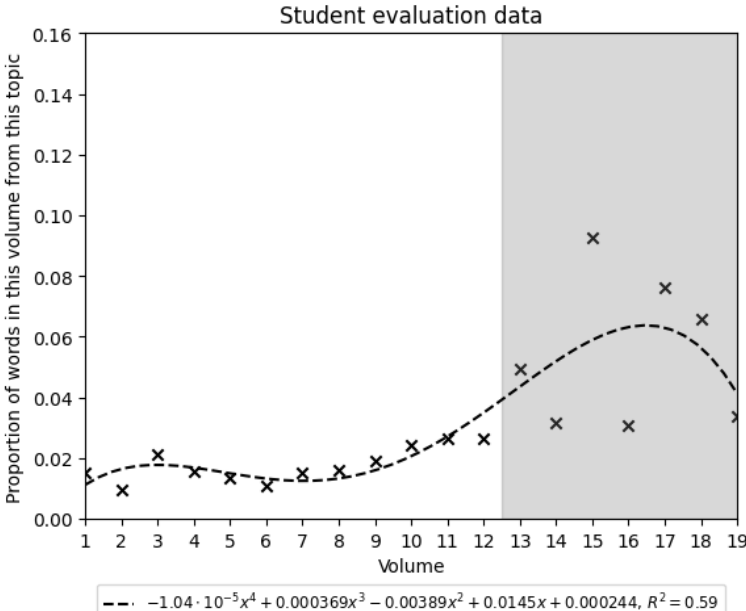

( $v)$

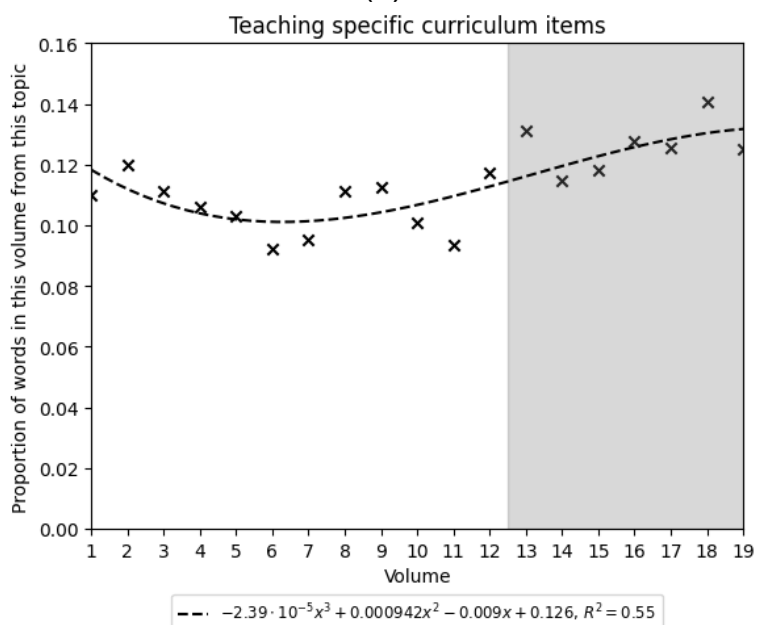

$(\mathrm{x})$

Figure 2. Proportion of words in each volume that relate to each topic. Trend lines are the polynomials with degree up to 5 that had the best fit (measured by $\mathrm{R}^{2}$ ). Shaded region represents the period since the MSOR Network closed and MSOR Connections was relaunched as a fully peer-reviewed practitioner journal. 


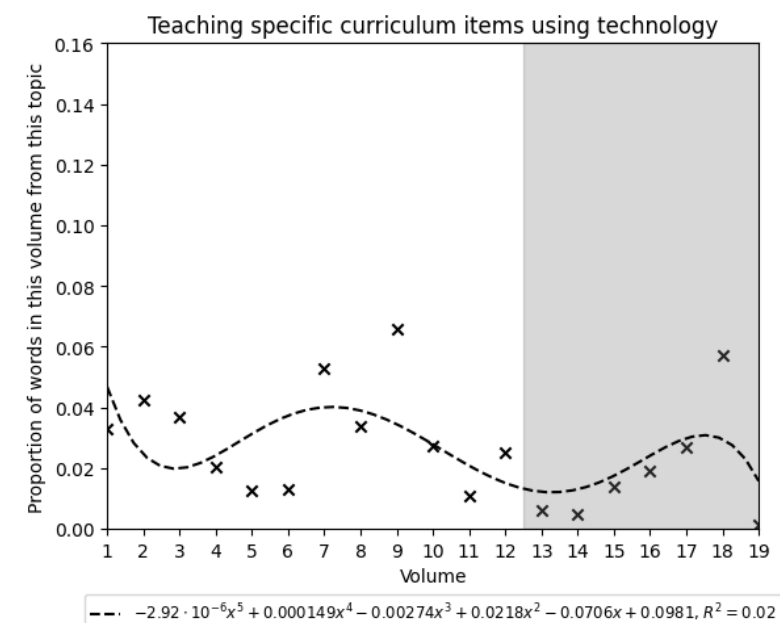

(y)

Figure 2. Proportion of words in each volume that relate to each topic. Trend lines are the polynomials with degree up to 5 that had the best fit (measured by $R^{2}$ ). Shaded region represents the period since the MSOR Network closed and MSOR Connections was relaunched as a fully peer-reviewed practitioner journal.

Next we briefly outline relevant context for each topic.

Assessment: Articles covering assessment as a general topic (e.g. lannone and Simpson, 2012), as well as specific methods (e.g. peer assessment is discussed by Brignell et al., 2019).

Book and software reviews: Articles reviewing books or software, which used to be systematically organised by the MSOR Network. As a consequence of the Network's closure, this topic has declined in popularity (Figure 2(b)).

Computational software: Articles describing features of software and its use for teaching, including in software reviews.

Conferences and workshops: The key articles here are a mixture of adverts/announcements and reports from those attending or running such events.

Digital and remote learning: Includes articles concerned with online videos, screen annotations, and similar technologies. Note that the plot of popularity over time (Figure 2(e)) shows a sudden increase in volume 19, as articles related to the COVID-19 pandemic start to emerge (Heraty, 2021; Jones, Meyer and Huang, 2021).

E-assessment question design: Two topics emerged around e-assessment. We felt from examining the most relevant papers that this one related more to the design of questions for e-assessment systems for particular purposes, for example Martin and Greenhow (2004) discuss the design of questions to assess topics in linear algebra.

E-assessment systems and technologies: This second e-assessment topic seems to relate more to general features of systems and technologies. For example, Kawazoe and Yoshitomi (2017) discuss the design and development of an e-learning and e-assessment system. 
Game play, outreach and the interaction of the two: This topic is a slight breakdown in the analysis, because it seems the relevant articles matched cover both outreach and widening participation (e.g. Easson, 2010) and use of games in higher education including for teaching game theory (Khan, 2017), which we would view as distinct topics. It's possible these have been grouped by the model due to some overlap around the use of games in mathematics communication (see, e.g., Steckles, Rowlett and Ugonna, 2020). We considered listing these as two categories, but ultimately decided this was not in the spirit of the project and anyway would severely complicate the analysis, for example the plot of occurrence of this topic over volume numbers in Figure 2(h) would no longer apply. Ultimately, it is a feature of the method that it uses no understanding of the topics involved and an analysis of topics in MSOR Connections using this method suggests that authors are writing articles about game play, outreach and their interaction which can be linked together, so that is what we report.

Graduate employability and skills development: This covers articles about the concept of employability and general initiatives (e.g. Hibberd and Grove, 2006) as well as specific teaching initiatives targeting skills development (e.g. Chadwick, Sandiford and Percey, 2011).

Interactive lecture technology, including classroom voting systems: Methods for increasing interactivity and engagement in lectures, particularly using voting technologies (e.g. Retkute, 2009).

Mathematics on the web, including impact on accessibility: These articles either relate to accessibility specifically (e.g. Maddox, 2007), or discuss the presentation of mathematics on the web, where increased accessibility is usually lauded as an advantage (e.g. Kaye, 2006).

Maths support interventions to improve confidence and address anxiety: Two topics appeared to relate to maths support. We felt this one related more to interventions, often delivered by maths support staff, that were designed to improve students' confidence and address maths anxiety (e.g. Ahmed, Joy and Moriarty, 2013), research informing such approaches (e.g. Sheffield and Hunt, 2007), and training designed to prepare tutors to deliver such interventions (e.g. Fitzmaurice et al., 2016).

Maths support provision: This second maths support topic appears to relate more to the organisation of a maths support centre or other provision (e.g. Croft and Robinson, 2003), and surveys of such provision (e.g. Ahmed, Davidson, et al., 2018).

Modelling, simulation and industrial problems: Articles relating to modelling and simulation topics, including those relating to simulated industrial problems (e.g. Chi, Pepper and Spedding, 2004).

Online resources: Articles here relate to online resources, particularly projects that generate and share such resources (e.g. Matthews and Croft, 2011).

Personal reflections of students and staff: The main articles in this topic cover a range of areas, but we feel the aspect that they have in common is that they were reflective and written from either the student (e.g. Harris, 2011) or staff (e.g. Baxter, 2005) perspective, or presented qualitative data from students (e.g. Thomlinson, Challis and Robinson, 2009).

Problem-solving and mathematical approaches: This includes articles about teaching problemsolving skills (e.g. Jones and Megeney, 2019) as well as articles about encouraging mathematical approaches to topics and problems, particularly in pre-service mathematics teachers (e.g. Bu and Haciomeroglu, 2010). 
Proof, skills and understanding: This includes articles about topics such as proof (e.g. Alcock, 2009), modelling and estimation (Maasz, 2007) and applications of geometry (Arranz et al., 2009), which all seem to be written from the point of view of developing understanding. This topic also includes articles about the nature of mathematics and mathematical identity (e.g. Bangert, 2005), and the skill of mathematical writing (Hodges, 2004).

School-university transition: Mostly the top relevant articles discuss changes to the A-level curriculum in England from the point of view of informing university practice at the transition (e.g. Porkess, 2003), but this topic is also concerned with teaching practice at the higher education side of the transition (e.g. Leppinen, 2008).

Staff development: Articles specifically about initiatives around staff development. This topic has declined somewhat since MSOR Connections is no longer the newsletter of the MSOR Network (see Figure 2(t)).

Statistical data analysis: The main papers matching this topic relate to teaching the interpretation of statistical results, often from specific software packages (e.g. Ramesh, 2009).

Student evaluation data: The main papers matching this topic were a mixture of studies using survey data as their methodology (e.g. Cronin et al., 2017) and papers discussing the use of surveys (e.g. Farmer, Oakman and Rice, 2016).

Student-centred approaches, including group work and peer support: The top articles here cover a number of different areas, but we feel what they have in common is that they develop student-centred approaches, which includes working in groups (e.g. Rowlett, 2013) and peer support arrangements (e.g. Cox, Cook and Nield, 2016).

Teaching specific curriculum items: This topic contains what appears to be a mixture of articles, but on looking through we feel the common thread is that they all cover a particular topic in mathematics or statistics and discuss the teaching of this (e.g. Steele, 2007), as well as some particular discussions around developing thinking skills (e.g. Mason and Watson, 2001). Note that all papers here are relatively low relevance compared to other topics, meaning that this topic is likely to be a secondary focus for even the most relevant articles.

Teaching specific curriculum items using technology: Similarly to the topic above, these articles discuss the delivery of specific parts of the curriculum, but especially using technology to do so (e.g. Hood, 2009).

\section{Discussion}

This paper has used an approach called topic modelling to generate a list of topics covered by articles in MSOR Connections during its first 20 years of publication. Articles are not linked to one topic, but are a combination of several. There are many standard topics that will not come as a surprise to readers and have remained of consistent popularity over the years. These include general teaching and learning topics: 'Assessment', 'Graduate employability and skills development' and 'School-university transition'. These also include mathematics-specific topics: 'Maths support provision', 'Modelling, simulation and industrial problems', 'Problem-solving and mathematical approaches', 'Proof, skills and understanding', 'Statistical data analysis' and 'Teaching specific curriculum items'.

MSOR Connections publishing comes in two phases: 2001-12, when it served as both the newsletter of the MSOR Network in the UK and a practitioner journal; and, 2013-present, when it was 
relaunched in its current form as a fully peer-reviewed practitioner journal with a more international focus. In the first phase, the publication included news from and content developed by the MSOR Network. Consequently, it is not surprising to see a reduction over time in the topics 'Book and software reviews', 'Conferences and workshops' and 'Staff development'.

In the 2013-present iteration, MSOR Connections included fewer, longer articles and was peerreviewed. Some changes in topic seem to align to this shift, including the rise in popularity of articles featuring 'Student evaluation data' and the slight reduction in focus on 'Personal reflections of students and staff', which together might indicate a greater focus on evidence-based practice in the current journal.

It is not surprising to see that a journal with a focus on innovative practice has a high degree of content about digital technology, with nine of the topics relating to this. As technology has developed, though, it seems natural that there may be a shift in focus away from novelties and features of software, as well as the reduction in coordinated activity with the removal of the MSOR Network. The reductions in popularity of the topics 'Computational software' and 'Online resources' seem to fit this progression. The reduction in the topic 'Mathematics on the web, including impact on accessibility' seems to fit this pattern also, with methods for displaying mathematics more mainstream and embedded in standard software. However, we would note that accessibility remains a challenge for mathematics and statistics, and hope that this focus will continue to be considered by authors.

Some other topics appear to have developed a subtlety as they mature, or possibly are more relevant to a peer-reviewed journal than previously. 'Maths support provision' remains popular, but the specific topic 'Maths support interventions to improve confidence and address anxiety' has risen in recent years. Similarly, while 'E-assessment systems and technologies' remains consistently popular (though with peaks in 2015 and 2017 when MSOR Connections collected articles from the EAssessment in Mathematical Sciences conferences), the specific interest of ' $E$-assessment question design' seems to have risen in popularity recently.

There has been a general rise in the topic 'Student-centred approaches, including group work and peer support', which may indicate a trend in undergraduate mathematics education practice towards a broader range of delivery and assessment approaches.

Finally, we reserve special comment for the topic 'Digital and remote learning', which has maintained a fairly consistent popularity over the years, but with an uptick in the first issue of volume 19 . We expect this topic, in itself and manifested in 'blended' approaches, to make a step-change in popularity over the coming issues as the short- and long-term consequences of increased remote working due to the COVID-19 pandemic make themselves known in the journal.

We are cautious about recommending implications following this research. First, it was our intention to hold a mirror up to the community and so to encourage self-evaluation by its members. Second, we are wary of an article co-authored by editor of the publication offering advice for those who might write content for it, as MSOR Connections looks to serve its community rather than direct its interests.

That said, we encourage readers to view the results here and consider the areas in which others are developing their practice. Potential authors might note that some topics have declined in popularity and consider whether this is because the field has matured and there is now less to say, or whether a topic is overdue a revival. It may be worth reflecting on the rise in interest in student-centred approaches, and the development of specific foci within student support and e-assessment, that may indicate developing interests of the community. Again, we leave it to the individual reader to judge 
whether this indicates a direction for their own practice or research, or whether they wish to develop alternative, understudied areas.

We might speculate about missing topics. One topic that does not occur in our analysis but which has a lot of current interest is equity, equality, diversity and inclusion. For example, in our country there have been recent mathematics-specific initiatives such as the Black Heroes of Mathematics Conference (Tabiri, 2021) and the LGBTQ+ STEMinar Conference series (https://lgbtstem.wordpress.com/lgbtsteminar-conference/) joining well-established work on women in mathematics (e.g. https://www.Ims.ac.uk/womeninmaths), as well as broader higher education conversations e.g. around decolonisation of the curriculum (Stone and Ashton, 2021). Such topics are also being discussed internationally. We might expect this general interest to develop into specific discussion by authors in this journal in the coming years.

The topic modelling method is somewhat context-independent, in that the allocation of words from articles into topics is done without knowledge of underlying context. This is a strength for unbiased analysis, meaning the groupings of key words and relevant articles is done without prejudice. This can, though, lead to the generation of topics we might not see as wholly linked, as is the case here where articles about game play and outreach are put together because of some overlap despite being quite disparate. And the method is not without potential bias: a different analysis could have been performed by choosing a different number of topics to analyse, and there is some interpretation by the authors in assigning names to the topics. It is also worth noting that our assessment of the different topics is based largely on the key words generated and the top articles matching that topic, which may mean that subtleties in the topics are lost, especially where these are common in articles that only moderately relate to a topic.

Overall, we hope this analysis has shone some light on the sorts of topics and trends in topics that the journal is experiencing, and that it will provide a call to action for authors wishing to either contribute their work on an existing topic or, perhaps more excitingly, write articles developing a new topic that has not surfaced in this research.

\section{References}

Ahmed, S., Davidson, P., Durkacz, K., Macdonald, C., Morgiane, R. and Walker, A, 2018. The Provision of Mathematics and Statistics Support in Scottish Higher Education Institutions (2017) A Comparative Study by the Scottish Mathematics Support Network. MSOR Connections, 16(3), pp. 5-19. https://doi.org/10.21100/msor.v16i3.798.

Ahmed, S., Foy, J. and Moriarty, D. (2013). An Evaluation of the Use of a Nursing Medication Formula Card as an Educational Tool. MSOR Connections, 13(1), pp. 41-44. Available via: https://www.advance-he.ac.uk/knowledge-hub/evaluation-use-nursing-medication-formula-cardeducational-tool [Accessed 23/06/2021].

Alcock, L. (2009). e-Proofs: Online resources to aid understanding of mathematical proofs. MSOR Connections, 9(4), pp. 7-10. Available via:

http://icse.xyz/mathstore/headocs/9407 alcock I eproofs.pdf [Accessed 23/06/2021].

Allan, C. (2000). How to ... Spread the word on best practice. Times Higher Education Supplement, 13 October. Available via: https://www.timeshighereducation.com/news/how-to-spread-the-wordon-best-practice/153788. article [Accessed 21/06/2021].

Arranz, J.M., Losada, R., Mora, J.A. and Sada, M. (2009). Realities from GeoGebra. MSOR Connections, 9(2), pp. 17-23. 
Bangert, P.D. (2005). In Search of Mathematical Identity. MSOR Connections, 5(4), pp. 33-35. Available via: http://icse.xyz/mathstore/headocs/5433mathematicalid.pdf [Accessed 23/06/2021].

Baxter, P.D. (2005). One year on - Reflections of a new lecturer. MSOR Connections, 5(2), pp. 1517. Available via: http://icse.xyz/mathstore/headocs/52oneyear.pdf [Accessed 23/06/2021].

Blake, J. Editorial. MSOR Connections, 4(4), p. 1. Available via: http://www.icse.xyz/mathstore/headocs/41intro.pdf [Accessed 21/06/2021].

Blake, J., Davies, N. and Bishop, P. (2000). Introduction to the LTSN. Maths, Stats \& OR, 1, p. 2. Available via: http://www.icse.xyz/mathstore/headocs/01ltsnint.pdf.

Brignell, C., Wicks, T., Tomas, C. and Halls, J. (2019). The impact of peer assessment on mathematics students' understanding of marking criteria and their ability to self-regulate learning. MSOR Connections, 18(1), pp. 46-55. https://doi.org/10.21100/msor.v18i1.1019.

$\mathrm{Bu}$, L. and Haciomeroglu, E.S. (2010). GeoGebra in mathematics teacher education: the case of quadratic relations. MSOR Connections, 10(1), pp. 6-9. Available via:

http://www.icse.xyz/mathstore/headocs/10106bu I geogebraquadratic.pdf [Accessed 29/06/2021].

Chadwick, E., Sandiford, K. and Percey, D. (2011). Assessing student teams developing mathematical models applied to business and industrial mathematics. MSOR Connections, 11(3), pp. 22-24. http://icse.xyz/mathstore/headocs/Connections 113 Chadwick.pdf [Accessed 23/06/2021].

Chi, X., Pepper, M. and Spedding, T. (2004). Web-Based Virtual Factory for Teaching Industrial Statistics. MSOR Connections, 4(3), pp. 36-39. Available via: http://icse.xyz/mathstore/headocs/43virtual factory.pdf [Accessed 23/06/2021].

Cox, S., Cook, L. and Nield, S. (2016). Peer Assisted Study Support (PASS) and Students as Change Agents (SACA) in Mathematics at the University of Nottingham. MSOR Connections, 14(3), pp. 39-44. https://doi.org/10.21100/msor.v14i3.313.

Croft, T. and Robinson, C. (2003). The Mathematics Education Centre at Loughborough University. MSOR Connections, 3(2), pp. 7-12. Available via: http://icse.xyz/mathstore/headocs/32mec.pdf [Accessed 23/06/2021].

Cronin, A.G., Ni Shuilleabhain, A., Lewanowski-Breen, E. and Kennedy, C. (2017). Maths Sparks: Investigating the impact of outreach on pupils attitudes towards mathematics. MSOR Connections, 15(3), pp. 4-13. https://doi.org/10.21100/msor.v15i3.535.

Easson, V. (2010). Widening participation in mathematics: an East London perspective. MSOR Connections, 10(2), pp. 22-25. Available via:

http://icse.xyz/mathstore/headocs/10222 easson v wp.pdf [Accessed 23/06/2021].

Farmer, R., Oakman, P. and Rice, P. (2016). A review of free online survey tools for undergraduate students. MSOR Connections, 15(1), pp. 71-78. https://doi.org/10.21100/msor.v15i1.311.

Fitzmaurice, O., Cronin, A., Ni Fhloinn, E., O'Sullivan, C. and Walsh, R. (2016). Preparing Tutors for Mathematics Learning Support. MSOR Connections, 14(3), pp. 14-21.

https://doi.org/10.21100/msor.v14i3.307. 
Griffiths, T.L. and Steyvers, M. (2004). Finding scientific topics. PNAS, 101, pp. 5228-5235. https://doi.org/10.1073/pnas.0307752101.

Hakim, L. (2010). Student Insert.... Integral equations in modelling crack propagation under creep and fatigue loading. MSOR Connections 10(3), p. 28.

Harris, A. (2011). When studying mathematics my biggest surprise was... MSOR Connections, 11(2), pp. 26-27. Available via: http://icse.xyz/mathstore/headocs/Harris.pdf [Accessed 23/06/2021].

Heraty, C., Mac an Bhaird, C., McGlinchey, A., Mulligan, P., O'Hanrahan, P., O'Malley, J., O'Neill, R. and Vivash, T. (2021). Technological Explorations in the Move to Online Mathematics Support. MSOR Connections, 19(1), pp. 55-62. https://doi.org/10.21100/msor.v19i1.1130.

Hibberd, S. and Grove, M. (2006). A Response to the Royal Society paper: Science Higher Education in 2015 and beyond - call for evidence. MSOR Connections, 6(3), pp. 36-39. Available via: http://icse.xyz/mathstore/headocs/6336s hibberdandm grove.pdf [Accessed 23/06/2021]

Hodges, W. (2004). An experimental course in mathematical writing. MSOR Connections, 4(3), pp. 29-31. Available via: http://www.icse.xyz/mathstore/headocs/43mathematical writing.pdf [Accessed 29/06/2021].

Hood, D. (2009). Numerical solution of ordinary differential equations using an MS ExcelC spreadsheet. MSOR Connections, 9(3), pp. 34-37. Available via:

http://icse.xyz/mathstore/headocs/9334 hood d excelode.pdf [Accessed 23/06/2021].

lannone, P. and Simpson, A. (2012). How do we assess our students? A survey of current assessment practices in UK universities. MSOR Connections, 12(1), pp. 7-10. Available via: http://icse.xyz/mathstore/headocs/Connections 121 lannone.pdf [Accessed 23/06/2021].

Inglis, M. and Foster, C. (2018). Five Decades of Mathematics Education Research. Journal for Research in Mathematics Education, 49(4), pp. 462-500.

https://doi.org/10.5951/jresematheduc.49.4.0462.

International Centre for Statistical Education (2016). ICSE Closure. Available via: http://www.icse.xyz/?p=584 [Accessed 21/06/2021].

Jones, D., Meyer, J. and Huang, J. (2021). Reflections on remote teaching. MSOR Connections, 19(1), pp. 47-54. https://doi.org/10.21100/msor.v19i1.1137.

Jones, M. and Megeney, A. (2019). Thematic problem solving: a case study on an approach to teaching problem solving in undergraduate mathematics. MSOR Connections, 17(2), pp. 54-59. https://doi.org/10.21100/msor.v17i2.978.

Kawazoe, M. and Yoshitomi, K. (2017). E-learning/e-assessment systems based on webMathematica for university mathematics education. MSOR Connections, 15(2), pp. 17-24. https://doi.org/10.21100/msor.v15i2.416.

Kaye, R. (2006). Why (and how) I am using XML and MathML. MSOR Connections, 6(1), pp. 2022. Available via: http://icse.xyz/mathstore/headocs/6120xmlmathml.pdf [Accessed 23/06/2021]. 
Khan, S.N. (2017). Using a simple poker game to introduce mixed strategies in game theory. MSOR Connections, 16(1), pp. 36-44. https://doi.org/10.21100/msor.v16i1.650.

Kyle, J. (2013a). Editorial. MSOR Connections, 13(1), pp. 1-2.

Kyle, J. (2013b). Editorial. MSOR Connections, 13(2), pp. 1-2.

Leppinen, D., (2008). Reflections upon the teaching of Mechanics to first year university students. MSOR Connections, 8(1), pp. 3-6.

http://icse.xyz/mathstore/headocs/8103 leppinen d mechanics.pdf [Accessed 23/06/2021].

Maasz, J. (2007). Cars and Calculation: Some Proposals for Teaching Real World Mathematics. MSOR Connections, 7(1), pp. 4-8. Available via: http://icse.xyz/mathstore/headocs/Maasz.pdf [Accessed 23/06/2021].

Maddox, S. (2007). Mathematical equations in Braille. MSOR Connections, 7(2), pp. 45-48. Available via: http://icse.xyz/mathstore/headocs/Maddox S.pdf [Accessed 23/06/2021].

Marks, R., Foster, C., Barclay, N., Barnes, A. and Treacy, P. (2021). A comparative synthesis of UK mathematics education research: what are we talking about and do we align with international discourse? Research in Mathematics Education, 23(1), pp. 39-62.

https://doi.org/10.1080/14794802.2020.1725612.

Martin, E. and Greenhow, M. (2004). Setting objective tests in linear algebra using QM Perception. MSOR Connections, 4(3), pp. 49-53. Available via:

http://icse.xyz/mathstore/headocs/43QM perception.pdf [Accessed 23/06/2021].

Mason, J. and Watson, A. (2001). Getting Students to Create Boundary Examples. MSOR Connections, 1(1), pp. 9-11. Available via: http://icse.xyz/mathstore/headocs/11boundary.pdf [Accessed 23/06/2021].

Matthews, J. and Croft, T. (2011). Sharing mathematics support resources - the mathcentre Community Project. MSOR Connections, 11(2), pp. 37-39. Available via:

http://icse.xyz/mathstore/headocs/Matthews.pdf [Accessed 23/06/2021].

McCallum, A.K. (2002). MALLET: A Machine Learning for Language Toolkit. Available via: http://mallet.cs.umass.edu [Accessed 21/06/2021].

Porkess, R. (2003). The new AS and A Levels in Mathematics. MSOR Connections, 3(4), pp. $12-$ 16. Available via: https://www.advance-he.ac.uk/knowledge-hub/new-and-levels-mathematics [Accessed 23/06/2021].

Ramesh, N. (2009). The role of Minitab in teaching and learning statistics. MSOR Connections, 9(3), pp. 9-13. Available via: http://icse.xyz/mathstore/headocs/9309 ramesh $n$ minitabrole.pdf [Accessed 23/06/2021].

Retkute, R. (2009). Exploring Technology-Based Continuous Assessment via Electronic Voting Systems in Mathematics and Statistics. MSOR Connections, 9(1), pp. 24-28. Available via: http://icse.xyz/mathstore/headocs/9124 retkute $r$ evs.pdf [Accessed 23/06/2021].

Rowlett, P. (2013). A Modification of Bradshaw's Method of Group Allocation When You Do Not Know the Students. MSOR Connections, 13(2), pp. 43-50. Available via: https://www.advance- 
he.ac.uk/knowledge-hub/modification-bradshaw\%25E2\%2580\%2599s-method-group-allocationwhen-you-do-not-know-students [Accessed 23/06/2021].

Sheffield, D. and Hunt, T. (2006). How Does Anxiety Influence Maths Performance and What Can We do About It? MSOR Connections, 6(4), pp. 19-23. Available via:

http://icse.xyz/mathstore/headocs/6419 anxietymaths.pdf [Accessed 23/06/2021].

Steckles, K., Rowlett, P. and Ugonna, A. (2020). Pre-university informal engagement with mathematical activities and the decision to study mathematics at university. MSOR Connections, 18(3), pp. 10-22. https://doi.org/10.21100/msor.v18i3.1048.

Steele, C. (2007). The false revival of the logarithm. MSOR Connections, 7(1), pp. 17-19.

Stone, R.V. and Ashton, S. (2021). How not to decolonise your curriculum. WonkHE, 7th April. Available via: https://wonkhe.com/blogs/how-not-to-decolonise-your-curriculum/ [Accessed 24/06/2021].

Tabiri, A. (2021). Black Heroes of Mathematics Conference. Mathematics Today, 57(2), p. 42.

Thomlinson, M., Challis, N. and Robinson, M. (2009). Student experiences of the transition to university. MSOR Connections, 9(2), pp. 48-51. Available via:

http://icse.xyz/mathstore/headocs/9248 thomlinson m etal mmgtransition.pdf [Accessed 23/06/2021].

Tyrrell, S. (2009). Book Review... SPSS for Dummies by Arthur Griffin. MSOR Connections 8(4), p. 38.

Waller, D. (2012). Editorial. MSOR Connections, 12(2), p. 1. Available via:

http://www.icse.xyz/mathstore/headocs/Connections 122 ContentsandWelcome.pdf [Accessed 21/06/2021].

Wilson, R. (2015). Editorial. MSOR Connections, 14(1), pp. 2-3.

https://doi.org/10.21100/msor.v14i1.263. 